\title{
The effectiveness of group trauma management therapy on the reduction of traumatic bereavement symptoms in bereaved female senior high school students
}

\author{
Nasrollah Moeini ${ }^{\circledR}$, Sajjad Basharpoor ${ }^{\circledR}$, Nader Hajlu, Mohammad Narimani \\ Department of Psychology, University of Mohaghegh Ardabili, Ardabil, Iran
}

*Corresponding Author: Sajjad Basharpoor, Associate Professor, Department of Psychology, University of Mohaghegh Ardabili, Ardabil, Iran. Tel: 00989141402212,Email: basharpoor_sajjad@uma.ac.ir

\begin{abstract}
Background and aims: One of the important issues that bereaved students are faced with is the symptoms that they experience after the death of their loved one. Consequently, this can reduce their performance in various aspects of life, including education. The present study aimed to investigate the effectiveness of group trauma management therapy (GTMT) in reducing the traumatic bereavement symptoms of bereaved female students.

Methods: This study was an experimental research with pretest-posttest control group design. The statistical population of the present study included all the bereaved senior high school female students of Iranshahr in the school year of 2016-2017. Forty subjects were selected among the whole population using the simple random sampling method. After conducting a clinical interview, to confirm the symptoms of bereavement, the selected individuals were randomly assigned to two experimental group $(n=20)$ and control group $(n=20)$. The Hogan Grief Reaction Checklist (HGRC) was used to collect the data. To analyze the obtained data, the descriptive statistics and multivariate analysis of covariance (MANCOVA) tests were applied using SPSS software.

Results: The results indicated the effectiveness of trauma management therapy (TMT) in decreasing despair $(P<0.001)$, panic $(P<0.001)$, anger and blame $(P<0.001)$, detachment $(P<0.001)$, disorganization $(P<0.001)$, and personal growth $(P<0.001)$.

Conclusion: Considering the effect of GTMT on the reduction of traumatic bereavement symptoms among bereaved students, this method can be used as an effective treatment for relieving and reducing the traumatic bereavement symptoms.

Keywords: Group trauma management therapy (GTMT); Traumatic bereavement symptoms; Female senior high school students
\end{abstract}

Received: 7 March 2018, Accepted: 2 November 2018, ePublished: 7 December 2018

\section{Introduction}

Bereavement is an inevitable part of human life and human beings may produce severe behavioral, emotional, and cognitive responses when faced with the death of their loved ones. Grief, defined as an inner experience in response to the lack of precious and loving things, can lead to the loss of control and the experience of exhausting emotions such as fear, loneliness, lack of identity, and other difficult emotions (1).

Following the death of a loved one, children and adolescents usually experience a wide range of emotions and behaviors. They often show the feelings of anger and cowardliness. Some of them lose their passion for previously enjoyable activities and they may show aggressive and destructive behaviors. They may also experience loss of appetite, sleep disorders, isolation, fatigue, restlessness, aggression, learning difficulties and lack of interest in the school activities. They may lose their concentration or even go back to the earlier periods of growth, and this can have a negative effect on their school performance (2).
In addition, the death of a family member or a close friend puts the bereaved individual at high risk for experiencing several types of psychiatric disorders, including the major depressive disorder, generalized anxiety disorder, posttraumatic stress disorder (PTSD), and increased alcohol abuse (3).

Bereaved individuals may experience countless emotions. Among these emotions are anxiety, depression, hopelessness (4), lower levels of well-being, lower quality of life (5), feeling of anger (6), difficulty in expressing excitement (7), emotional dysregulation such as the difficulty in accepting the reality of loss and feeling of losing meaning in life (8), and feeling guilty (9-11).

Despite the fact that traumatic bereavement affects several functional aspects of the behavior, especially in children and adolescents, few clinical studies have been conducted on potentially beneficial therapies for children and adolescents who undergo trauma.

One of the proposed treatments for intervention in traumatic events is trauma management therapy (TMT). 
TMT is a multi-component behavioral program, which was originally designed by Frueh et al, to identify the various aspects of chronic PTSD in military veterans. In general, this treatment is more effective in reducing anger, social isolation, depression and guilt, reducing emotional and physiological responses to trauma symptoms, reducing disturbing symptoms and avoidance behavior, improving interpersonal skills and adjusting emotions (such as anger management), improving vocational adjustment, and increasing the range of pleasurable social activities $(12,13)$. TMT include exposure therapy, programmed practice, social and emotional rehabilitation, social reintegration, anger management, and brief behavioral activation $(14,15)$. The results related to the effectiveness of the trauma management therapy in people exposed to stressful and traumatic events indicate that this treatment is effective in reducing a vast range of problems in soldiers with post-traumatic stress disorder (12-15).

Facing some traumatic and challenging incidents is inevitable in children and adolescents, but without essential support and guidance, timely diagnosis and treatment, individuals may become very sensitive to their emotional, cognitive and developmental effects, and achieving a particular developmental milestone can be difficult (16). Given that trauma management therapy is a multi-component treatment, it is assumed that it can reduce the post-traumatic symptoms in individuals with various traumas, including traumatic loss. Therefore, this study aimed to investigate the effect of trauma management therapy on the reduction of post-traumatic symptoms in bereaved students.

\section{Materials and Methods}

The present study was an experimental research with a pretest-posttest control group design. The statistical population of the study included all the bereaved senior high school female students of Iranshahr in the school year of 2016-2017. First, in order to determine the number of students faced with the loss and bereavement, 500 individuals (about one-third of the population) were selected using the multi-stage cluster sampling and evaluated by the Hogan Grief Reaction Checklist (HGRC). A total of 106 individuals got a score higher than the cut score (174.65). After conducting a structured clinical interview, to verify the symptoms of bereavement, some participants were eliminated, and 40 subjects were selected randomly from the remaining people. Then, the sample members were randomly assigned to the 2 experimental $(n=20)$ and control groups $(n=20)$. The reason for choosing 20 people in each group is that the minimum sample for the pilot projects is 15 people (17). In this research, 20 subjects were selected for each group to increase the credibility and prevent the subjects from dropping out of the study. The group trauma management therapy (GTMT) was performed on the participants in the experimental group during 12 sessions, while the control group did not receive any intervention.

The inclusion criteria of the study included: being senior high school student, being at the age range of 14-18, giving written consent by the students and their parents to participate in the study, and their commitment to active participation until the end of the treatment. The exclusion criteria consisted of the absence of more than 2 sessions and lack of the participants' interest in the intervention. The following instruments were used to collect the data:

Demographic questionnaire: This questionnaire was designed to collect the demographic information of the participants. In this section, the participants were asked about their age, field of study, grade, socio-economic status (family income level, housing status, parents' education status, parents' employment), the deceased person, and the time of the death.

The HGRC: This is a self-reported checklist consisting of 61 items, which evaluates several common reactions to the bereavement. The items of this scale provide a list of the common thoughts and feelings among the bereaved ones. The respondents are asked to specify the severity of their emotions over the past 2 weeks based on a 5-point Likert scale (from $1=$ it does not describe me at all, to $5=$ it describes me very well). Hence, the score of this scale ranges from 61 to 305 . The underlying sub-scales of this checklist include: despair, panic behavior, blame and anger, detachment, disorganization, and personal growth. In the study of Hogan et al, Cronbach a coefficient for the subscales of despair, panic behavior, personal growth, blame and anger, detachment, and disorganization has been reported as $0.89,0.90,0.82,0.79,0.87$, and 0.84 , respectively. In this study, the internal consistency method was applied to calculate the initial validity of the HGRC by calculating Cronbach $\alpha$. The validity coefficients for the whole scale and for the subscales of despair, panic behavior, personal growth, blame and anger, detachment, and disorganization were reported to be $0.90,0.87,0.84$, $0.82,0.79,0.87$, and 0.84 , respectively (18).

For data collection, after obtaining the ethical approval (IR.ARUMS.REC.1396. 231) from the Ardabil University of Medical Sciences and getting permission from the Ministry of Education in Iranshahr and selecting the statistical sample, the researcher referred to the considered schools and the participants were asked to respond collectively to the demographic questionnaire and the HGRC. Then, with those who scored higher than the cut score, a structured clinical interview was conducted for the diagnosis of post-traumatic stress disorder in children and adolescents. Some people did not show these symptoms and were excluded. In the next stage, 40 subjects were randomly selected and randomly assigned to 2 experimental and control groups.

One of the preconditions for covariance analysis is the homogeneity of variance. In this study, the significance 
level of Levene test is greater than 0.05 (0.32). It can be said that the variance of the groups is consistent. The data were analyzed using descriptive statistics and multivariate analysis of covariance (MANCOVA), using the SPSS software version 22.0 .

The trauma management treatment program was held during weekly meetings (twice a week) for 75 minutes per session. This program was designed based on the trauma management treatment of Frueh et al (12) and Turner et al (13). A summary of the intervention sessions is presented in Table 1.

\section{Results}

Table 2 shows the frequency of the subjects based on the demographic variables of the field of study and the grade.

Table 3 shows the mean and standard deviation of the time of death and age.

Descriptive analysis was reported using the mean and standard deviation and MANCOVA was employed for data analysis.

Table 4 shows the mean and standard deviation of the subjects' scores in the greif variable and its subscales.

The results in Table 5 show that the difference between the 2 groups is $0.75 \%$ with regard to the dependent variables (ETA coefficient in Wilks' lambda $=0.75$ ). That

Table 1. Summary of treatment sessions

Trauma Management Therapy
Session 1: Introduction of the treatment method and running the pre-test
Sessions 2, 3, \& 4: Exposure skills training (visual and factual), planned
exercise, and relaxation training
Sessions 5 \& 6: Socio-environmental self-awareness skills and promotion
of the interpersonal skills
Sessions 7 \& 8: Social integration training (preserving relationships with
Family, Friends and so on)
Sessions 9, 10, \& 11: Anger management, problem solving, and brief
behavioral activation for depression and guilt feeling
Session 12: Summing up the whole sessions and reviewing the
feedbacks and implementing the post-test

Table 2. Results of demographic information of the subjects in groups

\begin{tabular}{|c|c|c|c|c|c|}
\hline \multirow{2}{*}{ Groups } & \multirow{2}{*}{$\begin{array}{l}\text { Sample } \\
\text { size }\end{array}$} & \multicolumn{2}{|l|}{ Field of Study } & \multicolumn{2}{|l|}{ Grade } \\
\hline & & Field & No. & Grade (class) & No. \\
\hline \multirow{3}{*}{ Experimental } & \multirow{3}{*}{20} & \multirow{2}{*}{ Humanities } & \multirow{2}{*}{11} & First & 5 \\
\hline & & & & Second & 11 \\
\hline & & Science & 9 & Third & 4 \\
\hline \multirow{3}{*}{ Control } & \multirow{3}{*}{20} & \multirow{2}{*}{ Mathematics } & \multirow{2}{*}{10} & First & 10 \\
\hline & & & & Second & 6 \\
\hline & & Science & 10 & Third & 4 \\
\hline
\end{tabular}

Table 3. Mean and standard deviation of age and time of death

\begin{tabular}{lcc}
\hline Variables & $\begin{array}{c}\text { Experimental } \\
\text { Mean } \pm \text { SD }\end{array}$ & $\begin{array}{c}\text { Control } \\
\text { Mean } \pm \text { SD }\end{array}$ \\
\hline Age (year) & $16.55 \pm 1.19$ & $16.20 \pm 0.69$ \\
Time of death (month) & $6.37 \pm 3.15$ & $6.97 \pm 2.97$ \\
\hline
\end{tabular}

is, $0.75 \%$ of the total variance of the differences between the 2 groups is related to the dependent variables of this study.

The results in Table 6 indicate that after controlling the effects of pre-test, there is a significant difference between the post-test scores of the 2 groups in each of the variables of despair $(P<0.001)$, panic behavior $(P<0.001)$, blame and anger $(P<0.001)$, detachment $(P<0.001)$, disorganization $(P<0.001)$ and total score $(P<0.001)$.

\section{Discussion}

The present study was conducted to investigate the effectiveness of TMT in reducing the symptoms of grief in bereaved students. The results indicated that TMT is effective in reducing the trauma symptoms in bereaved students $(P<0.001)$.

The results of the present study are consistent with the findings of some researchers who showed the effectiveness of TMT in alleviating a broad spectrum of difficulties in combat veterans with chronic PTSD (19). Some other researchers (13) also conducted a study on the effect of TMT on the reduction of PTSD symptoms and combatrelated illusions and the results indicated the effectiveness of this kind of treatment. One of the researchers (14) showed that TMT significantly decreases the overall PTSD symptoms as well as the combat-themed hallucinations in veterans. The results of this study are also in line with a study done by Beidel et al (15) who showed that the TMT was an effective treatment method in reducing the PTSD symptoms of soldiers participated in the Operation Iraqi Freedom.

In addition, since TMT combines individual exposure therapy with other behavioral techniques (15), and due to the fact that today trauma-focused cognitive-behavioral therapies are of great use for the people who have experienced trauma (20), this treatment can be used to reduce the grief symptoms.

In this regard, the results of the present study are consistent with the results of some other studies. In a study, Cohen and Mannarino (21) showed that traumafocused cognitive-behavioral therapy can reduce the psychological problems of children and adolescents who have experienced various types of traumatic events. In another study, Cohen et al (20) showed that this treatment method, which includes all behavioral management strategies, can effectively manage the behavioral regulation problems that commonly occur in traumatized children. Unfortunately, no study has been conducted on potentially beneficial therapies of children and adolescents with traumatic bereavement. However, one of the treatments that can help children and adolescents is TMT that can affect many aspects of the bereaved person's life.

\section{Conclusion}

The results show that TMT has a significant effect on 
Table 4. Mean and standard deviation of the subjects' scores in the grief variable and its subscales

\begin{tabular}{|c|c|c|c|c|}
\hline \multirow{3}{*}{ Sub-scales } & \multicolumn{2}{|c|}{ Experimental } & \multicolumn{2}{|c|}{ Control } \\
\hline & Pre-test & Post-test & Pre-test & Post-test \\
\hline & Mean \pm SD & Mean \pm SD & Mean \pm SD & Mean \pm SD \\
\hline Despair & $50 \pm 7.97$ & $21.70 \pm 3.04$ & $50.45 \pm 5.86$ & $44.50 \pm 10.76$ \\
\hline Panic behavior & $52.10 \pm 8.55$ & $22.50 \pm 3.41$ & $50.65 \pm 8.51$ & $47.75 \pm 12.44$ \\
\hline Anger \& blame & $20.35 \pm 4.94$ & $10.70 \pm 1.62$ & $22.65 \pm 6.48$ & $22.75 \pm 8.33$ \\
\hline Detachment & $30.40 \pm 4.84$ & $12.60 \pm 2.06$ & $28.65 \pm 5.38$ & $22.25 \pm 8.41$ \\
\hline Disorganization & $24.40 \pm 5.89$ & $10.55 \pm 2.23$ & $24.80 \pm 4.52$ & $22.80 \pm 7.37$ \\
\hline Personal growth & $39.20 \pm 7.64$ & $42.70 \pm 4.26$ & $37 \pm 7.61$ & $34.05 \pm 9.38$ \\
\hline Total score & $216.45 \pm 19.02$ & $109.55 \pm 12.20$ & $214.20 \pm 23.39$ & $197.10 \pm 38.07$ \\
\hline
\end{tabular}

Table 5. The results of MANCOVA tests for comparing the mean scores of the 2 groups of subject in the grief variable and its subscales

\begin{tabular}{|c|c|c|c|c|c|c|}
\hline Sources & Value & $F$ & $d f$ hypothesis & $d f$ error & $P$ value & ETA coefficient \\
\hline Pillai's trace & 0.75 & 13.89 & 6.00 & 27.00 & 0.001 & 0.75 \\
\hline Wilks' lambda & 0.24 & 13.89 & 6.00 & 27.00 & 0.001 & 0.75 \\
\hline Hotelling trace & 3.09 & 13.89 & 6.00 & 27.00 & 0.001 & 0.75 \\
\hline Roy's largest root & 3.09 & 13.89 & 6.00 & 27.00 & 0.001 & 0.75 \\
\hline
\end{tabular}

Table 6. The Results of MANCOVA tests for the comparison of the effect of TMT on the grief variable and subscales

\begin{tabular}{|c|c|c|c|c|c|c|c|c|}
\hline Source of the change & Dependent variable & Sum of squares & $d f$ & Mean squares & $F$ & $P$ value & Effect size & Statistical power \\
\hline \multirow{7}{*}{ Pre-test effect } & Despair & 0.05 & 1 & 0.05 & 0.000 & 0.99 & 0.000 & 0.05 \\
\hline & Panic & 1.04 & 1 & 1.04 & 0.01 & 0.92 & 0.000 & 0.05 \\
\hline & Anger \& blame & 0.40 & 1 & 0.40 & 0.01 & 0.92 & 0.000 & 0.05 \\
\hline & Detachment & 60.14 & 1 & 60.14 & 1.46 & 0.24 & 0.04 & 0.22 \\
\hline & Disorganization & 46.67 & 1 & 46.67 & 1.59 & 0.22 & 0.05 & 0.23 \\
\hline & Personal growth & 121.12 & 1 & 121.12 & 2.57 & 0.12 & 0.07 & 0.34 \\
\hline & Total score & 47.35 & 1 & 47.35 & 0.06 & 0.81 & 0.002 & 0.07 \\
\hline \multirow{7}{*}{ Group membership } & Despair & 4707.99 & 1 & 4707.99 & 69.34 & 0.001 & 0.68 & 1.00 \\
\hline & Panic & 5655.27 & 1 & 5655.22 & 58.92 & 0.001 & 0.65 & 1.00 \\
\hline & Anger \& blame & 1241.98 & 1 & 1241.98 & 31.42 & 0.001 & 0.49 & 1.00 \\
\hline & Detachment & 1462.28 & 1 & 1462.28 & 35.51 & 0.001 & 0.52 & 1.00 \\
\hline & Disorganization & 1403.51 & 1 & 1403.51 & 50.11 & 0.001 & 0.61 & 1.00 \\
\hline & Personal growth & 8.34 & 1 & 8.34 & 0.18 & $0 / 68$ & 0.006 & 0.07 \\
\hline & Total score & 76220.48 & 1 & 76220.48 & 93.01 & 0.001 & 0.71 & 1.00 \\
\hline
\end{tabular}

reducing the symptoms of bereavement. Therefore, such programs can be used to promote the health of children and adolescents. Lack of the long-term follow-up (due to the lack of availability of students at intervals after the implementation of this study, it was not possible to conduct follow-up studies) and the use of non-clinical samples were among the limitations of the present study. It is recommended that other bereaved samples, as well as the individuals with different traumas, be treated.

Conflict of interests

None.

Ethical considerations

Ardabil University of Medical Sciences approved the study (ethics code: IR.ARUMS.REC.1396.231).

Acknowledgments

In the end, the researchers really appreciate the efforts and cooperation of the education authorities in the Ministry of Education in Iranshahr who have contributed to this study. This paper is based on a doctoral dissertation (No. 2299) written by Nasrollah Moeini.

\section{References}

1. D'Antonio J. Caregiver grief and anticipatory mourning. J Hosp Palliat Nurs. 2014;16(2):99-104. doi: 10.1097/ njh.0000000000000027.

2. Fatahi R, Kalantari M, Mulavi H. Comparing the effectiveness of islamic grief therapy and program group grief therapy on the problems of extermination in teenage girls bereaved. Journal of Studies in Islam \& Psychology. 2014;8(15):39-64.[Persian].

3. Jacobs S, Mazure C, Prigerson H. Diagnostic criteria for traumatic grief. Death Stud. 2000;24(3):185-99. doi: $10.1080 / 074811800200531$.

4. Burke LA, Clark KA, Ali KS, Gibson BW, Smigelsky MA, Neimeyer RA. Risk factors for anticipatory grief in family members of terminally ill veterans receiving palliative care services. J Soc Work End Life Palliat Care. 2015;11(3-4):24466. doi: 10.1080/15524256.2015.1110071.

5. Al-Gamal E. Quality of life and anticipatory grieving among 
parents living with a child with cerebral palsy. Int J Nurs Pract. 2013;19(3):288-94. doi: 10.1111/ijn.12075.

6. Stroebe M, Schut H, Boerner K. Cautioning health-care professionals. Omega (Westport). 2017;74(4):455-73. doi: 10.1177/0030222817691870.

7. Diminich ED, Bonanno GA. Faces, feelings, words: divergence across channels of emotional responding in complicated grief. J Abnorm Psychol. 2014;123(2):350-61. doi: 10.1037/ a0036398.

8. Fernandez-Alcantara M, Cruz-Quintana F, Perez-Marfil MN, Catena-Martinez A, Perez-Garcia M, Turnbull OH. Assessment of emotional experience and emotional recognition in complicated grief. Front Psychol. 2016;7:126. doi: 10.3389/ fpsyg.2016.00126.

9. Li J, Stroebe M, Chan CL, Chow AY. Guilt in bereavement: a review and conceptual framework. Death Stud. 2014;38(15):165-71. doi: 10.1080/07481187.2012.738770.

10. Camacho D, Perez Nieto MA, Gordillo F. Guiltand Bereavement: Effect of the cause of death, and measuring instruments. Illness CrisisLoss.2017. doi:10.1177/1054137316686688.

11. Duncan C, Cacciatore J. A systematic review of the peer-reviewed literature on self-blame, guilt, and shame. Omega (Westport). 2015;71(4):312-42. doi: $10.1177 / 0030222815572604$.

12. Frueh BC, Turner SM, Beidel DC, Mirabella RF, Jones WJ. Trauma management therapy: a preliminary evaluation of a multicomponent behavioral treatment for chronic combatrelated PTSD. Behav Res Ther. 1996;34(7):533-43.

13. Turner SM, Beidel DC, Frueh BC. Multicomponent behavioral treatment for chronic combat-related posttraumatic stress disorder: trauma management therapy. Behav Modif.
2005;29(1):39-69. doi: 10.1177/0145445504270872.

14. Arens AM. Trauma management therapy for a veteran with co-occurring combat PTSD and hallucinations: A case study. Clin Case Stud. 2015;14(2):115-28. doi: 10.1177/1534650114541324.

15. Beidel DC, Frueh BC, Neer SM, Lejuez CW. The efficacy of Trauma Management Therapy: A controlled pilot investigation of a three-week intensive outpatient program for combatrelated PTSD. J Anxiety Disord. 2017;50:23-32. doi: 10.1016/j. janxdis.2017.05.001.

16. Bergeson CA. Supporting Children's Grief after a Death: A Guide for School Psychologists. Provo: Brigham Young University. 2012:51.

17. Delavar A. Theoretical and practical foundations of research in humanities and social sciences. Tehran: Roshd; 2013. [Persian].

18. Hugan NS, Greenfield, DB, Schmidt LA. Development and validation of the Hogan Grief Reaction Checklist. Death Stud. 2001; 25(1): 1-32. doi: 10.1080/07481180125831.

19. Frueh BC, Turner SM, Beidel DC, Mirabella RF, Jones WJ. Trauma management therapy: a preliminary evaluation of a multicomponent behavioral treatment for chronic combatrelated PTSD. Behav Res Ther. 1996;34(7):533-43.

20. Cohen JA, Berliner L, Mannarino A. Trauma focused CBT for children with co-occurring trauma and behavior problems. Child Abuse Negl. 2010;34(4):215-24. doi: 10.1016/j. chiabu.2009.12.003.

21. Cohen JA, Mannarino AP. Trauma-focused cognitive behavioural therapy for children and parents. Child Adolesc Ment Health. 2008;13(4):158-62. doi: 10.1111/j.14753588.2008.00502.x. 